\title{
Compression Behavior of Entrapped Gas in High Pressure Diecasting
}

\author{
Yasushi Iwata, Shuxin Dong, Yoshio Sugiyama and Hiroaki Iwahori
}

Toyota Central R\&D Labs., Inc., Nagakute 480-1192, Japan

Die castings generally contain a large quantity of porosities due to the entrapment of air or gas in molten metal during mold filling. Although the entrapped air or gas is compressed by high casting pressure during pressurization, it will eventually remain in the castings as defects after solidification. Therefore, it is important to clarify the relation between the volume of gas defects and the pressure applied to the molten metal so as to optimize the casting design.

In this study, we investigated the compression behavior of entrapped gas during casting. We determined the volume of gas defects and gas content in die castings by density measurement and vacuum fusion extraction method respectively. Then we calculated the gas pressure in the defects from the above volume of defects and gas content, and compared with the die casting pressure. The calculated gas pressure in the defects was found to be not equal to the die casting pressure, but equal to the pressure of the molten metal just before it dropped abruptly due to the complete blocking of the liquid metal channel by solidification. From the experimental results, the behavior of the entrapped gas can be inferred as follows. Immediately after the mold was filled with molten metal, the entrapped gas was instantly compressed. After that, the pressure of molten metal decreased gradually with the progress of solidification of the molten metal channel, and the volume of entrapped gas increased correspondingly until the pressure of the molten metal dropped abruptly. Then the volume of the entrapped gas showed a slight expansion equal to the solidification shrinkage of the enclosed molten metal.

The above inference was verified by measuring the volume of the entrapped gas defects in castings made with intentional depressurization carried out at the time when mold filling just finished or halfway through the solidification of the molten metal channel. [doi:10.2320/matertrans.F-M2011858]

(Received August 26, 2011; Accepted December 2, 2011; Published January 25, 2012)

Keywords: alloy, aluminum, die casting, casting defect, porosity, high pressure, solidification, quality control

\section{Introduction}

Die casting has been flourishingly applied to the automotive industry owing to its feature being able to manufacture intricate components with high efficiency. However, due to the high speed and high pressure mold filling of molten metal, die casting is generally disturbed by porosity defects arising from the entrapment of air or gases in the cavity of the mold. ${ }^{1,2)}$ It has been reported that the porosity defects can be reduced by increasing casting pressure in a number of researches. ${ }^{3-8}$ ) The effect of molten metal pressure at the end of mold filling (hereafter, is called molten metal pressure) on porosity defects was also recognized by the in-situ measurement of molten metal pressure. $^{9-12)}$ Although the optimization of the operating parameters of casting processes has been pursued by measuring molten metal pressure directly, there is still much to be desired for the components required of high performance. For instance, the behaviors of the entrapped gases during the pressurization, i.e. the volume change of the entrapped gases with the transmission and the attenuation of the molten metal pressure, has not been clarified, thus no effective measures can be taken to control such defects more precisely. In this study, we made an attempt to elucidate the effect of the molten metal pressure on gas porosities through analyzing the behaviors of gas porosities from the amount of the entrapped gases and the volume of porosities obtained from a plate-shaped high pressure die casting made under various injection velocities and plunger pressures. Furthermore, the result was validated by observing gas porosities in die castings made by freezing the shape of gas porosities before and after the pressurization during die casting.

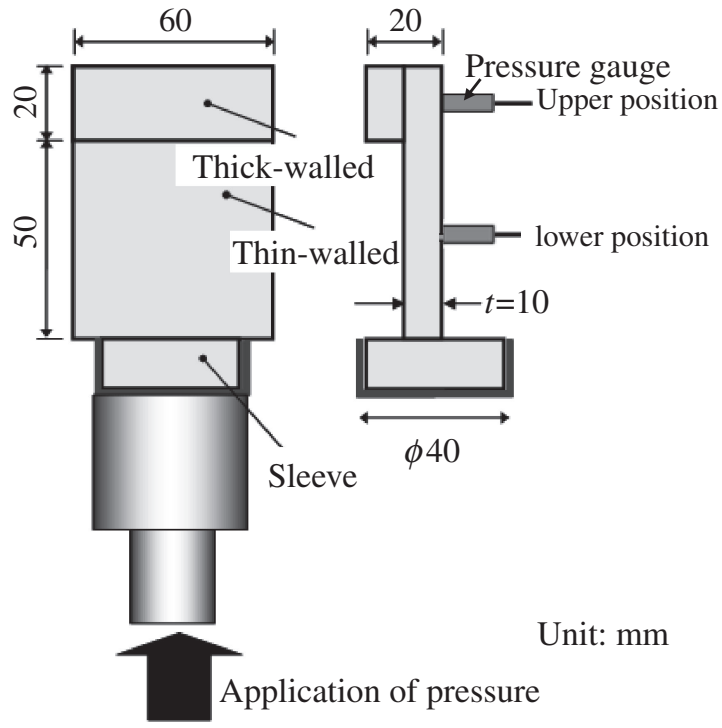

Fig. 1 Die casting for experiment.

\section{Experimental and Analyzing Methods}

\subsection{Die casting method of the experimental casting}

The experimental die casting, as is shown in Fig. 1, has a specially designed shape so that the transmission of the molten metal pressure from the pressurization part to the tip thick-walled part is constrained by the middle thin-walled part. The molten metal pressure of the thick-walled part of the die casting was measured by the diaphragm type pressure gauges (made by Dynisco Instruments Co., Ltd., the Rated highest functioning temperature: $773 \mathrm{~K}$, Highest pressure: 105.5 MPa) imbedded in the mold with the sensing surface of 
Table 1 Chemical composition of AD12.1 aluminum alloy.

\begin{tabular}{ccccccccc}
\hline $\mathrm{Si}$ & $\mathrm{Fe}$ & $\mathrm{Cu}$ & $\mathrm{Mn}$ & $\mathrm{Mg}$ & $\mathrm{Zn}$ & $\mathrm{Ni}$ & $\mathrm{Sn}$ & $\mathrm{Al}$ \\
\hline 11.62 & 0.88 & 2.89 & 0.34 & 0.21 & 0.93 & 0.05 & 0.02 & Bal. \\
\hline
\end{tabular}

the same height with the inner surface of the cavity. ${ }^{8)}$ The casting experiments were carried out in a vertical type die casting machine mounted with the mold of the experimental die casting. An aluminum alloy, JISAD12.1 melt was poured into the sleeve which was lined with a heat insulating layer (Kaowool made by Isolite Insulating Products Co., Ltd.) to prevent the initial solidification of the melt and injected at $953 \mathrm{~K}$. The chemical composition of the AD12.1 used for the present study is given in Table 1. In this experiment, mold releasing agent was not used to eliminate the effect of the gases emerging from the mold releasing agent on gas defects. The hydrogen content of the AD12.1 melt was measured from the ingots cast in the Ranseley Copper chill mold separately. The hydrogen content in the melt was measured as $2.5 \times 10^{-6} \mathrm{~m}^{3} / \mathrm{kgAl}$ and the total hydrogen amount in the tip thick-walled part of the die casting was calculated as $0.16 \times 10^{-6} \mathrm{~m}^{3}$, thus a very small value. The injection pressure and velocity were changed in the ranges of 15 $65 \mathrm{MPa}$ and $0.4-3.0 \mathrm{~m} \cdot \mathrm{s}^{-1}$ (the velocity at the thin-walled part of the cavity). The porosity volumes (absolute value) of the thick-walled part of the die castings were calculated from the differences between the densities of the thick-walled part and the true densities measured with separately cast samples. The gas content in the thick-walled part of the die casting was measured by melting the sample in an enclosed tube heated to $973 \mathrm{~K}$ in a tube furnace and converted to the value at $293 \mathrm{~K}$ and $0.1 \mathrm{MPa}$. The state of the porosity in the whole die casting was observed with a micro focus X-ray device (ACTIS-M330, with a $225 \mathrm{KV}$ demountable X-ray source, made by Tesco Co., Ltd.).

\subsection{The calculation of the volume change of gases}

The gases entrapped in the die castings were assumed totally coming from the air in the cavity of the mold and the gas solved in the melt was ignored. Therefore, the gas volume under pressurization in the die casting can be calculated by eq. (1), the van der Waals state equation of real gas, ${ }^{13)}$ from the gas amount at room temperature.

$$
\left(P+a / V^{2}\right)(V-b)=n R T
$$

Where, $P, V, T, n$ and $R$ are pressure, volume, temperature, mole of gas and gas constant respectively. $a, b$ are the van der Waals constants ${ }^{13)}$ and are determined depending on the kind of gases.

According to the principle of corresponding states (If two gases' states are corresponding, they exist in the same regime of the reduced form equation of state. Therefore, they will respond to changes in roughly the same way, even though their measurable physical characteristics may differ significantly.), eq. (1) can be expressed by the reduced form eq. (2) of gas state with the help of compression coefficient, $z$.

$$
P V=z n R T
$$

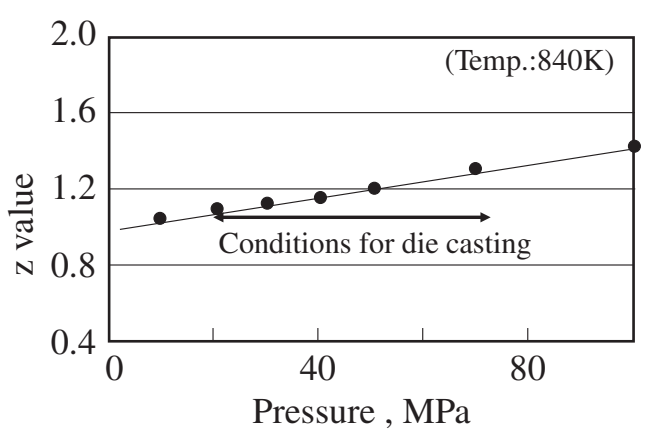

Fig. $2 \mathrm{Z}$ Value of air under die casting condition.

The $z$ values corresponding to the eutectic temperature, $840 \mathrm{~K}$ measured in this die casting experiment, and the pressure range under $100 \mathrm{MPa}$ are shown in Fig. 2. The $z$ values of air were obtained by the Lee and Kesler equation ${ }^{14)}$ from the corresponding state values of air at $840 \mathrm{~K}$. In the above calculation, the critical values of air were taken as the values of nitrogen which is the main component of the air and has a critical pressure of $3.14 \mathrm{MPa}$, a critical temperature of $126.3 \mathrm{~K}$, an eccentric factor of 0.04 . It can be seen from Fig. 2 that the $z$ values for the pressure range of $15-65 \mathrm{MPa}$ of this study are among $0.9-1.2$, thus eq. (3), the state equation for the ideal gas, can be used for the present experiment with a minor error.

$$
P V=n R T
$$

Therefore, in this study, the gas volumes were calculated with eq. (3). In the calculation, the temperature of the gas was assumed as $840 \mathrm{~K}$ which is the eutectic temperature of the cast alloy.

\subsection{The simulation method of the mold filling process}

The mold filling process of the experimental die casting shown in Fig. 1 was simulated under the same injection velocity as the casting experiment from the initial condition that the melt having the same volume as the casting had been poured in the sleeve. The simulation was done with the commercial code, FLOW3D (Product of Flow Science Co., Ltd.) by the FDM (Finite Difference Method) method with the model divided into $0.5 \mathrm{~mm}$ meshes. The slipping between the mold walls and the melt and the temperature drop of the melt were neglected. The kinematic viscosity coefficient of the melt was taken as a constant of $0.11 \times 10^{-6} \mathrm{~m}^{2} / \mathrm{s}$ during the mold filling. The meshes corresponding to the partition plane were treated as porous elements. The amount of the residual gases in the thick-walled part of the die casting can be decreased by increasing the porosity of the porous elements. In this analysis, the porosity that gave the same residual gas amount as the experimental die casting was used. The schematic of the simulation model is shown in Fig. 3.

\section{Experimental and Simulation Results}

\subsection{Effects of the injection condition on the amount of the entrapped gases and the inner porosities}

Effects of the injection velocity and the maximum pressure of the melt on the volume of the inner porosities of the thick- 

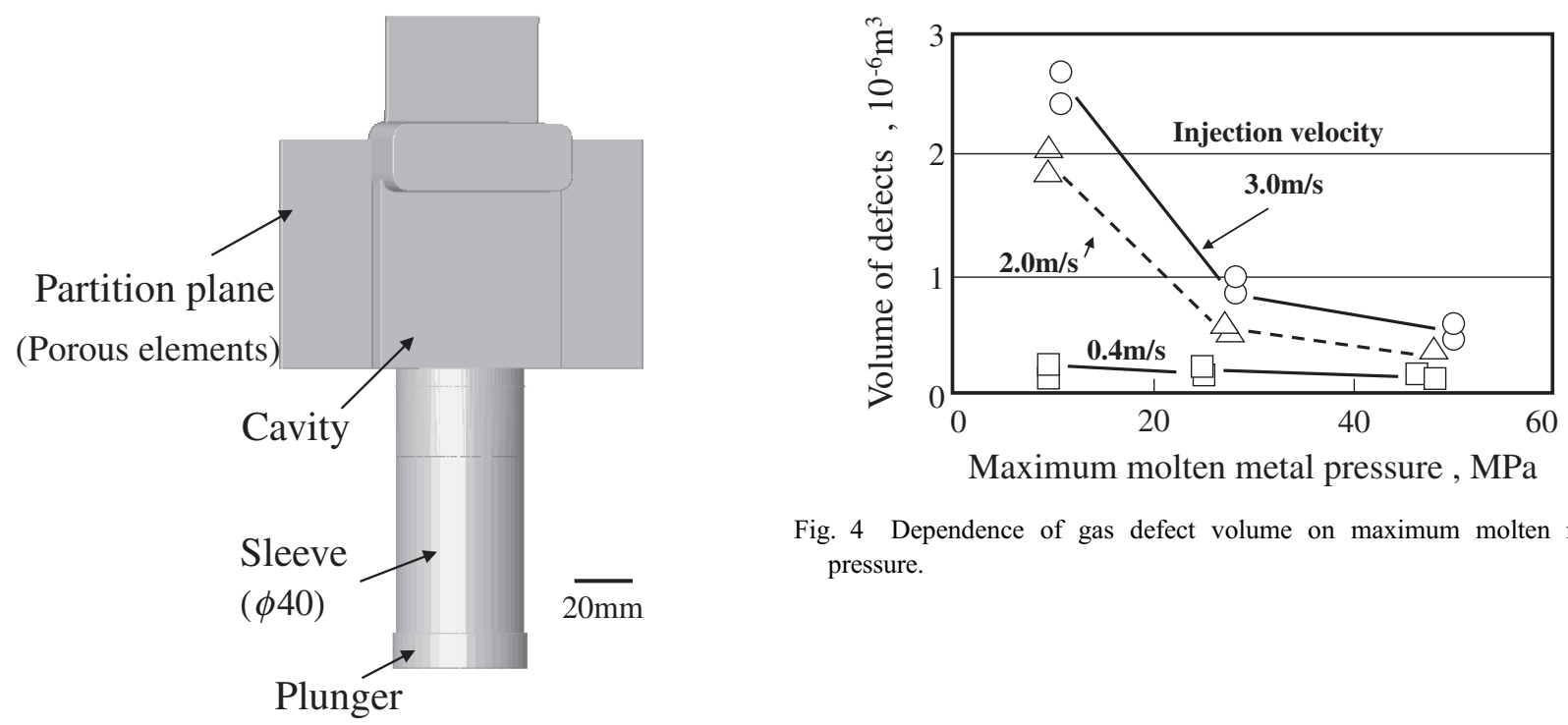

Fig. 4 Dependence of gas defect volume on maximum molten metal pressure.

Fig. 3 Model for molten metal flow simulation.

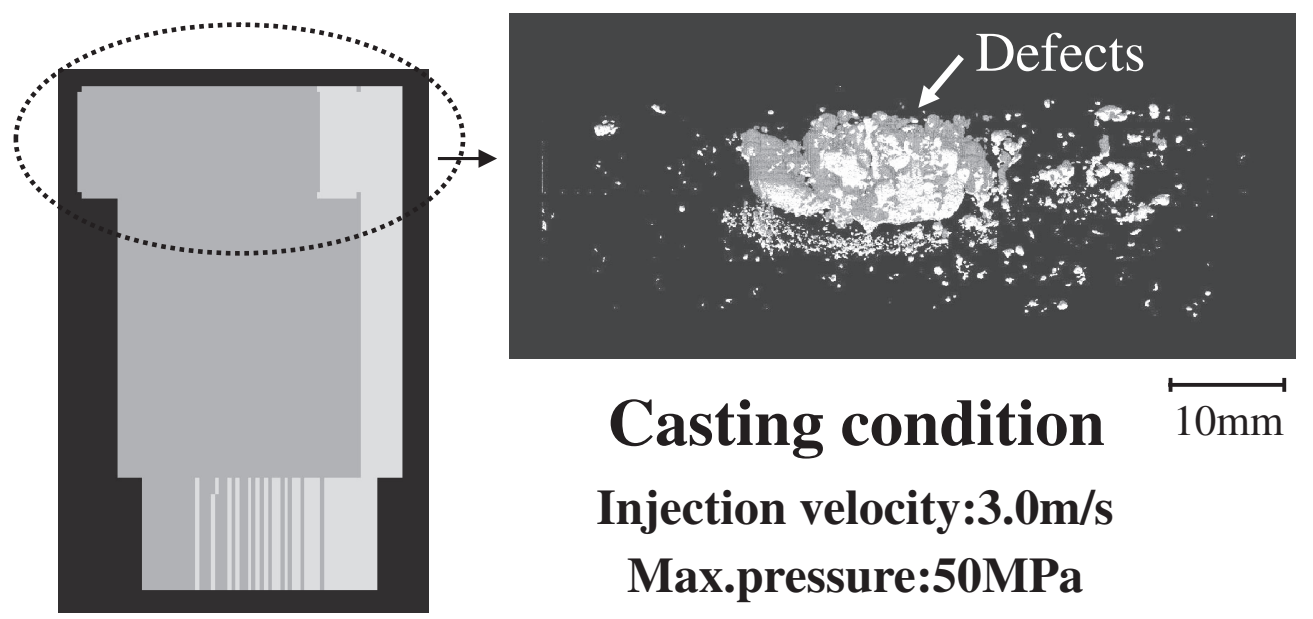

Fig. 5 Distribution of casting defects in thick-walled part.

walled part of the die castings are shown in Fig. 4. Where, the maximum pressure means the maximum value of the pressure applied to the melt in the cavity of the mold. The volumes of the inner porosities at an injection velocity of $0.4 \mathrm{~m} \cdot \mathrm{s}^{-1}$ had small values of $0.3 \times 10^{-6}$ to $0.4 \times 10^{-6} \mathrm{~m}^{3}$ and did not vary with the pressure of the melt. However, the volumes of the inner porosities rose with the increase of the injection velocity of the melt and reached a value of $2 \times 10^{-6}$ to $3 \times 10^{-6} \mathrm{~m}^{3}$ at an injection velocity of $3.0 \mathrm{~m} \cdot \mathrm{s}^{-1}$ and a melt pressure of $10 \mathrm{MPa}$. With the increase of the melt pressure, the volume of the inner porosities decreased and reached a value as low as $0.5 \times 10^{-6} \mathrm{~m}^{3}$ at $50 \mathrm{MPa}$. Figure 5 is the X-ray CT picture of the inner porosities of the thickwalled part of the casting made under the condition of an injection velocity of $3 \mathrm{~m} \cdot \mathrm{s}^{-1}$ and a melt pressure of $50 \mathrm{MPa}$. There exist a large porosity at the center part and some small porosities dispersing around the large porosity.

The amount of the entrapped gases in the thick-walled parts of the castings were measured and shown in Fig. 6. The amount of the entrapped gases increased with the increase of the injection velocity, but was not influenced by the casting

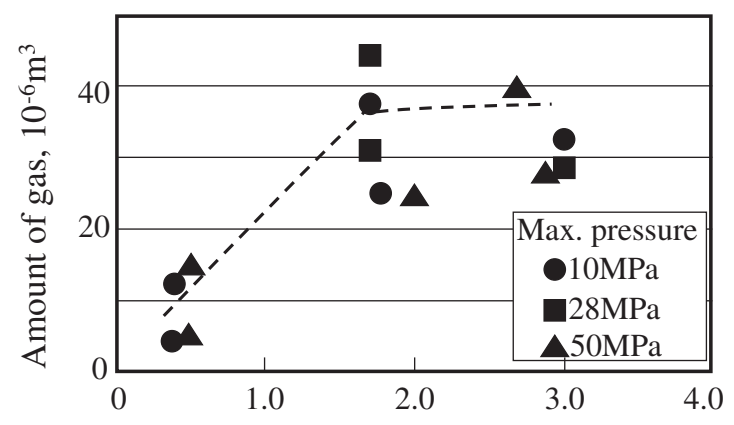

Injection velocity at thin walled part , $\mathrm{m} / \mathrm{s}$

Fig. 6 Dependence of gas amount on injection velocity.

pressure. The gas amounts were $10 \times 10^{-6} \mathrm{~m}^{3}$ and $40 \times 10^{-6}$ $\mathrm{m}^{3}$ at the injection velocities of 0.4 and $3 \mathrm{~m} \cdot \mathrm{s}^{-1}$ respectively.

Figure 7 shows the relations (black characters) of the inner porosity volumes of the thick-walled part of the castings and the injection velocities under different melt pressures. The volumes of the inner porosities decreased with the increase 
- $\mathbf{\Delta}$ Measured defect volume $\bigcirc \square \triangle$ Calculated defect volume from gas amount at $840 \mathrm{~K}$

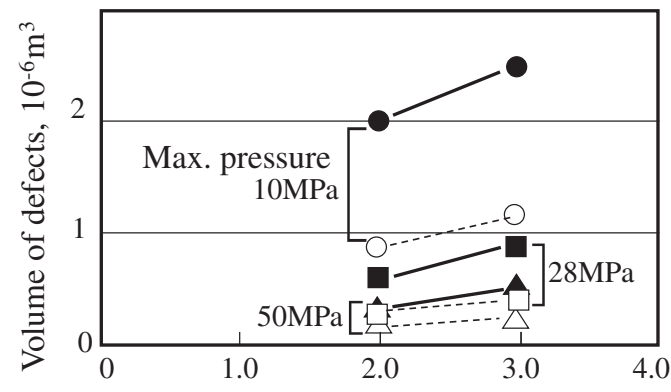

Injection velocity at thin walled part, $\mathrm{m} / \mathrm{s}$

Fig. 7 Comparison of defect volume measured and calculated from gas amount.

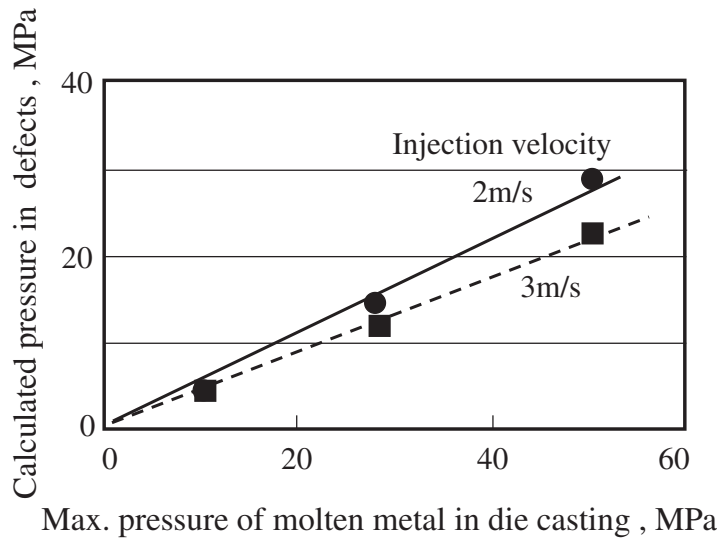

Fig. 8 Relation between calculated pressure and casting pressure.

of the casting pressure and showed a sharp decline when the casting pressure changed from 10 to $28 \mathrm{MPa}$. As is shown in Fig. 6, the amount of the entrapped gases is approximately constant at the same injection velocity, thus the inner porosity will be compressed to a comparatively small value under a higher molten metal pressure if the injection velocity is the same. Therefore, the gas volumes corresponding to these inner porosities under the maximum molten metal pressures were calculated from the gas amount shown in Fig. 6 with eq. (3) and plotted in Fig. 7. However, the calculated volumes of the inner gas porosities were just as small as half the measured values. That is to say, the real pressure in the inner porosities was not equal to the maximum value of the molten metal pressure. The real pressures of the inner gas porosities were calculated from the volumes of the inner porosities and the gas amounts at room temperature by eq. (3) and were shown in Fig. 8. It is obvious that the real gas pressures of the inner porosities are 40 to $50 \%$ the values of the maximum molten metal pressures for each case.

\subsection{The pressure of porosities}

The causes for the decline of the pressure in the porosities were investigated by comparing the curves of the molten metal pressure measured during die casting. The curves of the molten metal pressure for the castings having the maximum pressures of 28 and $50 \mathrm{MPa}$ respectively are shown in Figs. 9 and 10. The curves of the molten metal pressures show

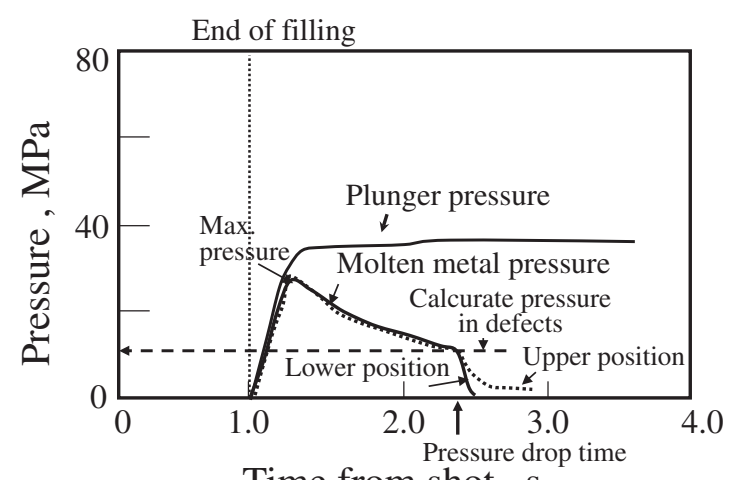

Time from shot, $\mathrm{s}$

Fig. 9 Molten metal pressure curves (Max. pressure: 28 MPa).

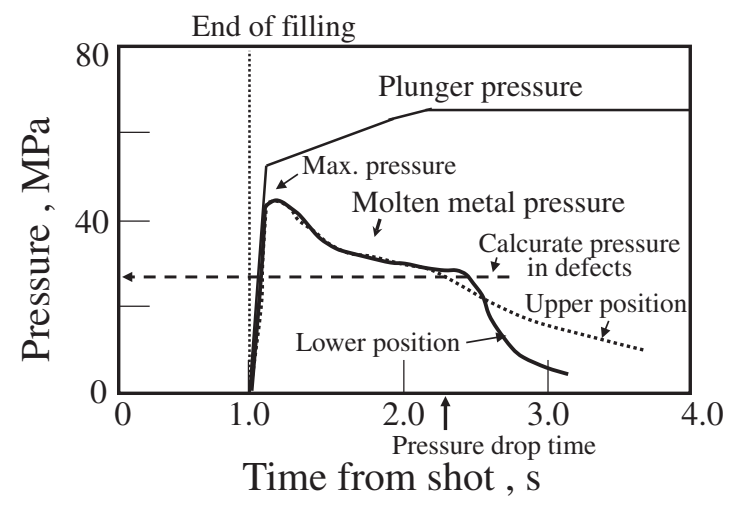

Fig. 10 Molten metal pressure curves (Max. pressure: $50 \mathrm{MPa}$ ).

almost the same variation tendency for different casting pressures, although the absolute values are different. That is to say, the molten metal pressures begin to rise and reach to a peak at 1 and $1.1 \mathrm{~s}$ respectively after the start of the injection of molten metal. After reaching the peak, the pressures of the molten metal decline with time and suddenly change to low levels at 2.3 to $2.4 \mathrm{~s}$. The sudden decrease of the molten metal pressure is considered to be attributed to the blocking of the molten metal channel by the solidification of the thin-walled part of the die casting. ${ }^{15)}$

The calculated pressure in the inner porosity of the castings made at an injection velocity of $3 \mathrm{~m} \cdot \mathrm{s}^{-1}$ is also illustrated in Figs. 9 and 10. This calculated pressure of the inner porosity is just equal to the value of the molten metal pressure at the time just prior to the sudden drop, i.e., the time just before the molten metal channel is blocked by the solidification of the thin-walled part of the casting. This behavior was observed not to vary with the maximum molten metal pressure, no matter the casting pressure was 28 or $50 \mathrm{MPa}$.

The calculation of the pressures in Figs. 9 and 10 was done as follows. Firstly, the residual molten metal and its amount of shrinkage of the thick-walled part of the die casting were calculated by solidification simulation at the time the molten metal channel was blocked by the solidification of the thinwalled part. The shrinkage amount of the residual molten metal was obtained as $0.15 \times 10^{-6} \mathrm{~m}^{3}$ for the die casting of a maximum molten metal pressure of $28 \mathrm{MPa}$. The final amount of the inner porosity (measured value) of the same 

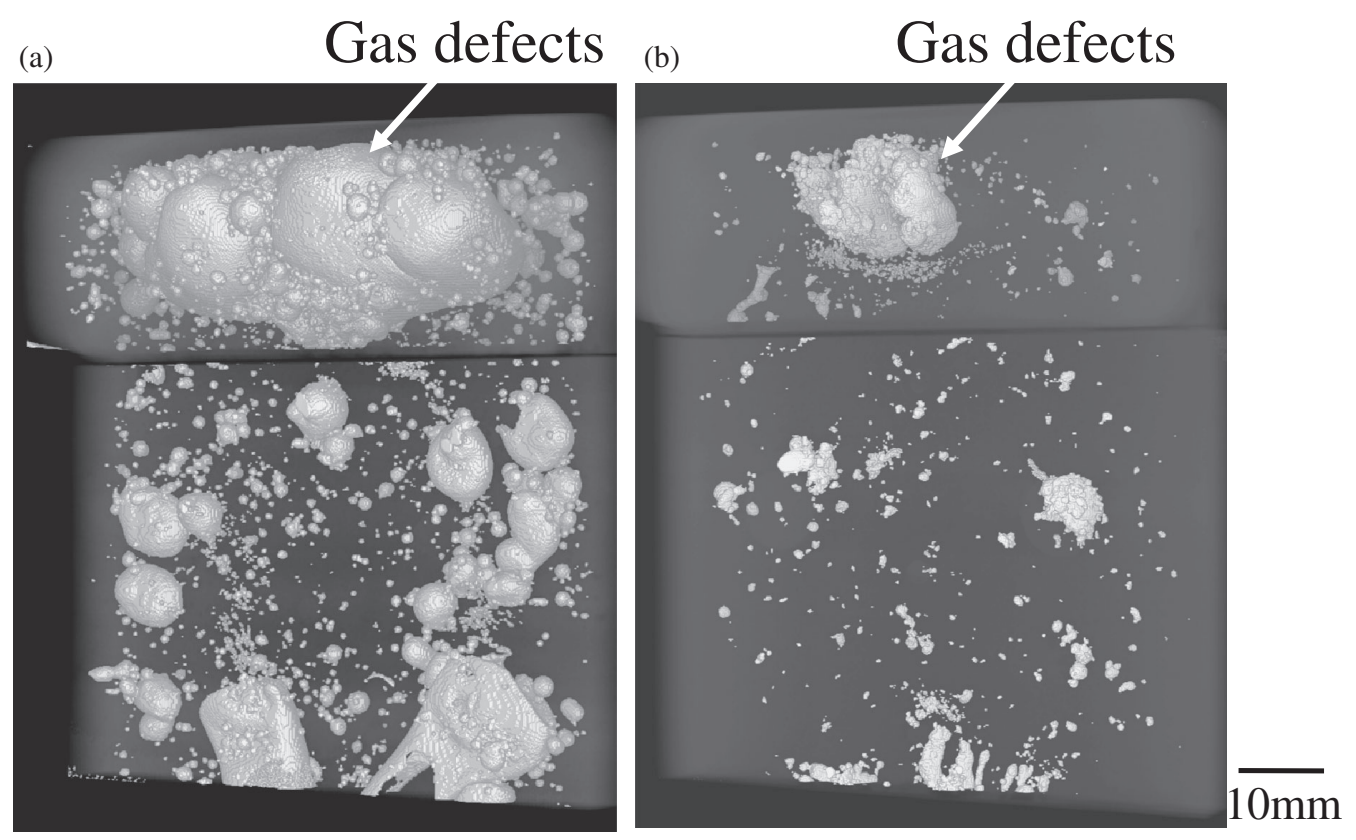

Fig. 11 Distribution of gas defects in castings depressurized at different time. (a) Depressurization time: at the end of filling (b) depressurization time: after application of pressure.

die casting can be found as $0.86 \times 10^{-6} \mathrm{~m}^{3}$ in Fig. 7 , thus the difference between the final amount of the inner porosity and the shrinkage of the residual molten metal, i.e., $0.86 \times$ $10^{-6} \mathrm{~m}^{3}-0.15 \times 10^{-6} \mathrm{~m}^{3}=0.71 \times 10^{-6} \mathrm{~m}^{3}$, can be considered as the volume of the entrapped gases at the time when the molten metal channel was blocked by the solidification of the thin-walled part of the die casting. The pressure in the inner porosity at this time was calculated as $13 \mathrm{MPa}$ with eq. (3) and was approximately equal to the measured pressure in the inner porosity.

As is shown in Fig. 6, $40 \times 10^{-6} \mathrm{~m}^{3}$ (measured under the condition of $0.1 \mathrm{MPa}$ and $293 \mathrm{~K}$ ) gases were entrapped in the casting when the filling velocity of melt was $3 \mathrm{~m} \cdot \mathrm{s}^{-1}$. When the maximum pressure of the molten metal just after the finish of the mold filling is $28 \mathrm{MPa}$ and the temperature of the entrapped gases are taken as the same temperature as the melt, $840 \mathrm{~K}$, the entrapped gases will be compressed to $0.4 \times 10^{-6} \mathrm{~m}^{3}$. However, after reaching the maximum value, the molten metal pressure declined and the compressed gases expanded to $0.71 \times 10^{-6} \mathrm{~m}^{3}$ at the time when the molten metal channel was blocked by the solidification of the thin-walled part of the die casting. After that, due to the solidification of the residual molten metal in the thick-walled part the entrapped gases further expand $0.15 \times 10^{-6} \mathrm{~m}^{3}$ which is equal to the shrinkage volume of the residual molten metal in the thick-walled part and the final volume of the inner porosities become $0.86 \times 10^{-6} \mathrm{~m}^{3}$.

\subsection{Observation of the compression behaviors of en- trapped gases}

To confirm the compression behaviors of the entrapped gases, in the die casting under the condition of Fig. 10, the plunger of the die cast machine was stopped just after the finish of the mold filling (at the time of $1.0 \mathrm{~s}$ in Fig. 10 when the pressure did not start to rise) and just before the blocking of the molten metal channel (at the time of $2.3 \mathrm{~s}$ in Fig. 10) respectively so as to freeze the inner porosities at those moments. The castings made by the above methods were observed by the 3D X-ray CT. The obtained 3D-CT graphs are shown in Figs. 11(a), 11(b). From Fig. 11(a), it can be seen that just after the finish of the mold filling, there were many large and small gas porosities in the whole casting no matter in the thick-walled part or the thin-walled part. The volume of these gas porosities was converted as $40 \times$ $10^{-6} \mathrm{~m}^{3}$ from the measured density of the casting. This volume of $40 \times 10^{-6} \mathrm{~m}^{3}$ accounts for $50 \%$ of the total volume $\left(78 \times 10^{-6} \mathrm{~m}^{3}\right)$ of the casting and the biscuit. On the other hand, the volume of the gas porosities just before the blocking of the molten metal channel was measured as $0.4 \times 10^{-6} \mathrm{~m}^{3}$ [Fig. 11(b)], thus the volume of the entrapped gases was compressed to one hundredth by the pressurization from the mold filling to the finish of pressurization.

Experimental castings were made with and without the plunger stopped just before the molten metal channel was blocked by the solidification of the thin-walled part $(2.3 \mathrm{~s}$ from the start of the mold filling in Fig. 10). The X-ray CT graphs of the castings are shown in Fig. 12. The porosities (the white areas) in the thick-walled parts of the two castings have the same projected areas, although there are some differences in the shapes of the porosities. The volumes of the porosities in the two castings were measured as $0.7 \times$ $10^{-6} \mathrm{~m}^{3}$ and $0.8 \times 10^{-6} \mathrm{~m}^{3}$ and were not so different. That is to say, the entrapped gases shown in Fig. 11(a) were compressed during the pressurization prior to the blocking of the molten metal channel by the solidification. After that, the porosities almost remained unchanged, except a small volume increase due to the solidification shrinkage.

The shapes of the porosities just after the mold filling in Fig. 11(a) are considered depending on the turbulence of the molten metal during the mold filling which is dominated by the injection velocity. To confirm the above experimental results, the mold filling processes were simulated and 


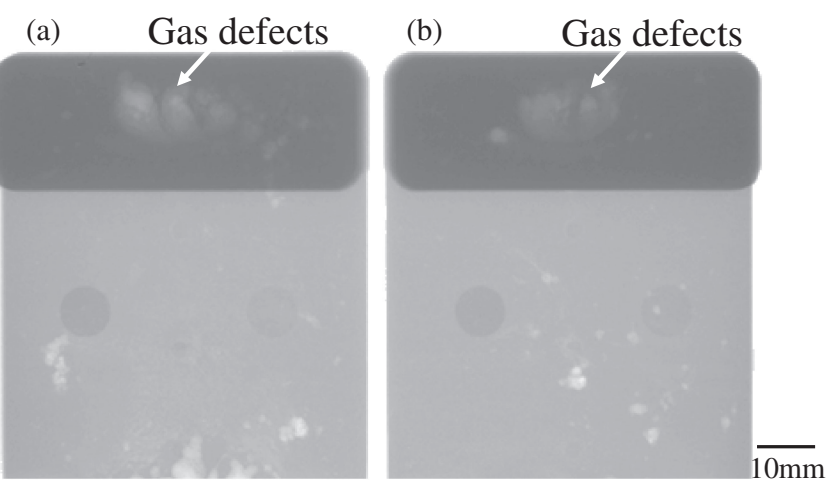

Fig. 12 Distribution of gas defects in castings with and without depressurization. (a) Castings with depressurization from $2.3 \mathrm{~s}$ (b) castings without depressurization.

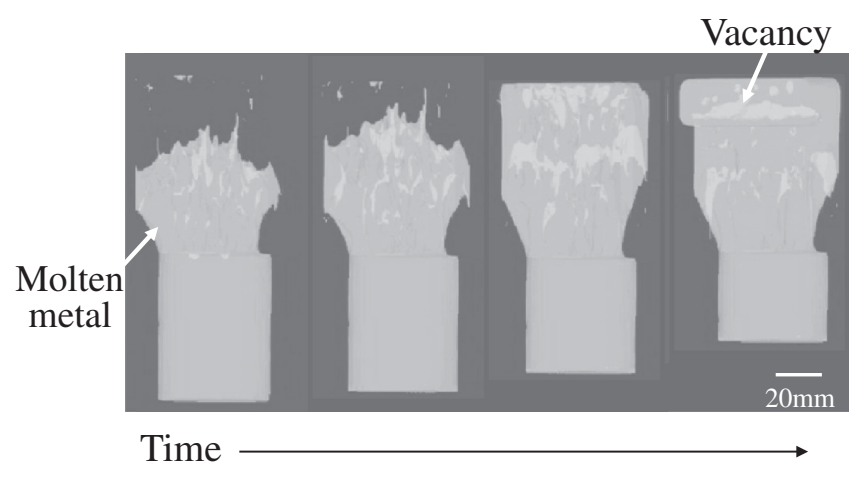

Fig. 13 Filling sequence of cavity by molten metal.

assessed for castings cast under different conditions. The simulation result for the casting cast under the same condition as that shown in Fig. 11(a) which had an injection velocity of $3 \mathrm{~m} \cdot \mathrm{s}^{-1}$ is illustrated in Fig. 13. The molten metal flows toward the thick-walled part of the casting and whirl into the mold cavity of the thick-walled part so as to entrap many large gas bubbles. Some spaces in the mold still remain unfilled in the vicinity of the entrance of the cavity, although the thick-walled part has been filled up. The final gas porosities in the casting predicted by the simulation are illustrated in Fig. 14. Most of the porosities form in the thickwalled part of the casting, while a few exist in the vicinity of the entrance of the mold cavity. The dispersion of the gas bubbles obtained by the simulation shows good correspondence to the experimental result given in Fig. 11(a) where the shapes of the porosities were frozen by stopping the plunger just after mold filling, thus it is confirmed that the state of the entrapped gases is as that shown in Fig. 11(a).

\section{Conclusions}

The following conclusions about the behaviors of the gas porosities in die castings were obtained by examining the measured gas amount, inner porosity volume with the state equation of gases and the transmission of the molten metal pressure.

(1) The compression coefficient of gases under the condition of die casting is small and the entrapped gases can be treated as the ideal gas with minor errors.

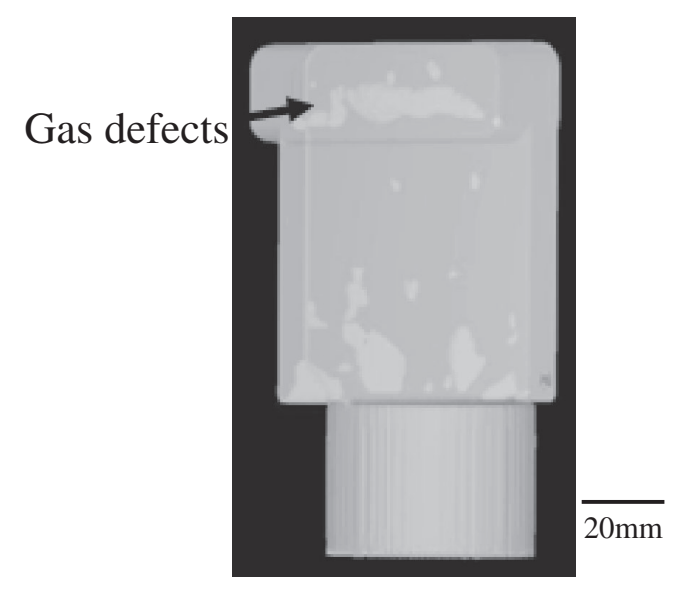

Fig. 14 Simulation result of gas defect distribution in castings.

(2) The pressure in the inner gas porosities is not equal to the maximum molten metal pressure, but equal to the pressure of the molten metal at the time just before the molten metal channel is blocked by the solidification.

(3) At the injection of melt, gas entrapment happens in the whole mold cavity especially in the thick-walled part. The volume of the entrapped gases shows the minimum value when the molten metal pressure reaches the maximum and expands with the decline of the molten metal pressure until the molten metal channel is blocked by the solidification of the thin-walled part. After that, the volume of the entrapped gases increases a little the amount of which corresponding to the solidification shrinkage of the residual liquid metal in the thick-walled part and becomes the final gas porosities remained in the die casting.

(4) The above behaviors of the entrapped gases were confirmed by freezing the shapes of the gas porosities in the pressurization processes.

\section{REFERENCES}

1) K. Tomita, H. Taniyama, M. Imabayashi and S. Iwamura: J. JILM 31 (1981) 186.

2) Y. Iwata, Y. Yamamoto and M. Nakamura: Light Metal 39 (1989) 550

3) K. Osasa, T. Takahashi and K. Kobori: J. Japan Inst. Metals 52 (1988) 1006-1011.

4) S. Okada and N. Fujii: SOGO IMONO 32 (1981) p. 5.

5) S. Okada and N. Fujii: SOGO IMONO 32 (1981) p. 13.

6) N. Nishi, Y. Ekoshi and K. Takahashi: Die Cast 86 (1987) 24.

7) Y. Sugiyama, H. Iwahori, K. Yonekura and Y. Okochi: IMONO 66 (1994) 412.

8) Y. Iwata, Y. Sugiyama, H. Iwahori and Y. Awano: J. JFS 72 (2000) 263.

9) K. Chichiiwa and K. Shiragami: IMONO 52 (1980) 641.

10) N. Nishi, H. Sasaki, T. Shirahara and K. Takahashi: IMONO 60 (1988) 777.

11) B. Guthrie and R. Whitbeck: Trans. 20th Int. Die Casting Congress and Exposition, (North America Association (NADCA), Rosemont, 1999) p. 241.

12) S. Tanikawa, K. Asai, Y. Yang, H. Nomura and E. Kato: J. JFS 77 (2005) 3.

13) T. Sakakibara, T. Yuasa, Y. Kawarabayashi, K. Sone, I. Kamiya and M. Yasuda: KAGAKUNOKISO, (Hirokawashouden, 1977) p. 25.

14) B. I. Lee and M. G. Kesler: AIChE J. 21 (1973) 510.

15) S. Tanikawa, K. Asai, Y. Yang, H. Nomura and E. Kato: J. JFS 75 (2003) 525 . 